\title{
Majorana in Naples
}

\author{
Bruno Preziosi $i^{1}$ \\ Dipartimento di Scienze Fisiche \\ Complesso Universitario di Monte S. Angelo, Via Cintia \\ 80126 Napoli, Italy
}

E-mail: bruno.preziosi@unina.it

The three months lived by Majorana in Naples are briefly described. His inaugural lecture, his students, the history of the lecture notes he gave, before his disappearance, to a student of his course and which were deposited in the Domus Galiaeana in a incomplete form are commented; the recent discovery of a complete copy of the same lectures, exactly coincident with the previous ones, when the comparison is possible, is also reminded. Finally, information in favour of the possibility that he retired in a monastery are given.

Ettore Majorana's legacy and the Physics of the XXI century

University of Catania, Italy

5-6 October, 2006

\footnotetext{
$1 \quad$ Speaker
} 


\section{Introduction}

The importance of Ettore Majorana's contribution to the development of the physical science has been described by many authors [1-5]. Many of them have also given detailed information about his collaboration with Enrico Fermi and the group of via Panisperna. In this brief report, I will only recall some aspects of his life during the three months he was in Naples.

I just recall that, on November 1937, he was appointed as full professor at the University of Naples by the minister Bottai, with an exceptional procedure. He arrived in Naples two or three days before January $12^{\text {th }} 1938$; in this day in fact he was supposed to give, as he did, his inaugural lecture. At that time, in fact, according to a procedure introduced in Naples for the first time on 1615 by the Earl of Lemos, viceroy in Naples during the Spanish kingdom, the new professors were obliged to give their first lecture in presence of the members of their Faculty. Among those who attended this lecture, there were some members of his family and, certainly, professor Antonio Carrelli, director of the Institute of Physics, and professor Renato Caccioppoli, a young and famous mathematician. In this lecture, he made a general review of the contents of the course in theoretical physics he had in mind to give, and were absolutely new for the University of Naples.

\section{Majorana's lectures}

Two days later, he gave his first lecture to the students, Nella Altieri, Laura Mercogliano, Nada Minghetti, Gilda Senatore and Sebastiano Sciuti. Also Savino Coronato, a young student in mathematics, who was going to get his degree on the same year with prof. Caccioppoli as adviser, attended all the lectures given by Majorana in his course. Gilda Senatore and Sebastiano Sciuti testify that none else attended the course, apart from a few occasional presences of Mario Cutolo, already graduated in physics.

The course went on regularly, except for a long interruption, between the second part of February and the first part of March, in connection with the presence in Naples of the King of Italy, Adolph Hitler and Benito Mussolini. The last lecture was given on March $24^{\text {th }}$.

Sixty years later, in 1998, we decided to organized a conference in memory of Majorana. In that occasion Vittorio Vaccaro, a colleague of mine, and Elio Tartaglione, who had been assistant of prof. Carrelli, proposed me to meet Gilda Senatore and I asked her to give the opening lecture of the conference. In that occasion, she told us:

On March $25^{\text {th }}$, not a lecture day, Majorana came exceptionally in the Institute. I was studying in our small class-room, when, from its entrance, he called me: "Signorina Senatore"; he did not enter. I went and he gave me a brief-case and said: "please, keep these papers, these notes,...we will discuss about them later"; after that, he went away and, turning back, repeated: "we will discuss about them later". He gave me no time to reply. On the other hand the next day, Saturday, was a lecture day; then I decided to wait for his return. But he didn't come any longer. 
After some days I was obliged, for personal reasons, to attend the Institute rarely. During the summer, I read in my house in Cava dei Tirreni all the notes; they were mainly concerning with the lectures he had given us, but there were also some pages which had nothing to do with them.

Only at the beginning of autumn, I could attend the Institute regularly again. Then I began my thesis work with prof. Francesco Cennamo; after more than one month, failing any news about prof. Majorana, I told him about the brief-case. Later I gave him all the notes and, after one or two months, he gave allof them to prof. Carrelli, who was charged as repository of Majorana materials.

Since then, Gilda Senatore had no news about the lecture notes.

Again, in 1998, Tartaglione told me also that, in the period ranging from 1953 to 1957, Cennamo revealed him that Carrelli, in occasion of a seminar in the Institute by Edoardo Amaldi, had given him Majorana's lecture notes.

Fortunately, Amaldi always kept the letters he received and a copy of the letters sent by him. All this material has been recently catalogued, so that Francesco Guerra, of the University of Rome, was able to reconstruct that on April $18^{\text {th }} 1950$ Carrelli invited Amaldi and on May $8^{\text {th }} 1950$ Amaldi replied proposing to give a seminar on the particle accelerators in the afternoon of next Saturday $13^{\text {th }}$.

Tartaglione remembers that, after the seminar, Carrelli and Amaldi remained in a room, alone, for more that two hours.

When in Roma, Amaldi surely showed the notes he received to his colleagues. In particular he gave them to Gilberto Bernardini, who was unable to recall where he had put them for many years. Finally, on the second of December 1964 he wrote:

Dear Edoardo, these are the pages of the Majorana's lectures that finally I have found, while clearing my office in Geneva,. They are incomplete. Probably Giovannino Gentile had the missing ones or they were never written...

What is known is that Amaldi, when received back the notes, decided to deposit them in the Domus Galilaeana in Pisa, where many documents concerning Galileo, his pupils and other Italian scientists are jealously guarded. Amaldi, with the agreement of Majorana's family, deposited there many other notes written by Ettore. These facts were well known, so that, when in 1987 the Department of Physical Sciences of the University of Naples decided to organize the annual Congress of the Italian Physical Society, I proposed to dedicate to Ettore Majorana a specific book. The direction of the Domus Galileana accepted that the lecture notes were photographed by a technician, so that it was possible to reproduce them anastatically in the book Ettore Majorana Lectures at the University of Naples [6]. Nicola Cabibbo accepted to comment both them and the notes for the inaugural lecture, discovered by Erasmo Recami in Majorana's house in Rome and published in the same book. He emphasized once more that the notes were incomplete. Finally, Recami reconstructed in the last part of the book both the history of the Majorana's family and many information concerning the life of Ettore and the circumstances of his disappearance.

In 2003 Salvatore Esposito and Antonino Drago received by their friend Cesare Moreno a manuscript of the notes of the Majorana lectures left by his father Eugenio Moreno, who had been a student of Renato Caccioppoli and graduated in mathematics in 1941. When Esposito informed me about this discovery, I suggested him to send an article to Il Nuovo Saggiatore [7]. The article was published at the beginning of 2005. In this 
article two pages of the manuscript by Moreno are

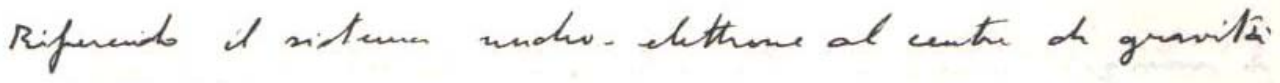

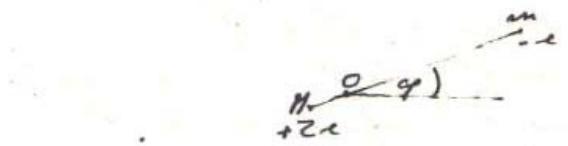

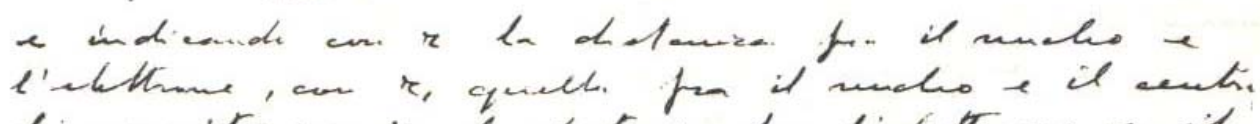

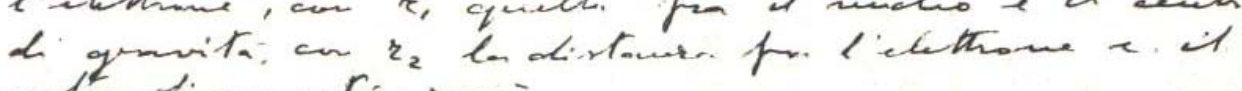

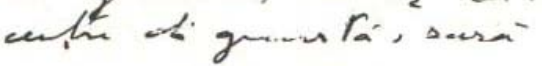

$$
r_{1}=\frac{m}{M+m_{1}} r_{2}=\frac{M}{M+m}
$$

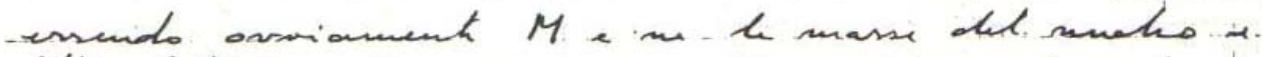

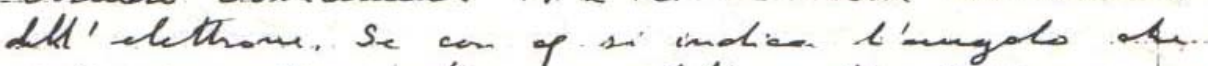

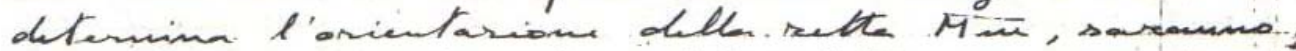

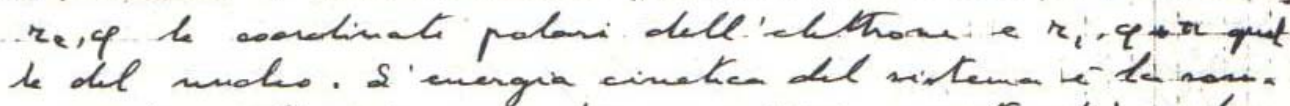

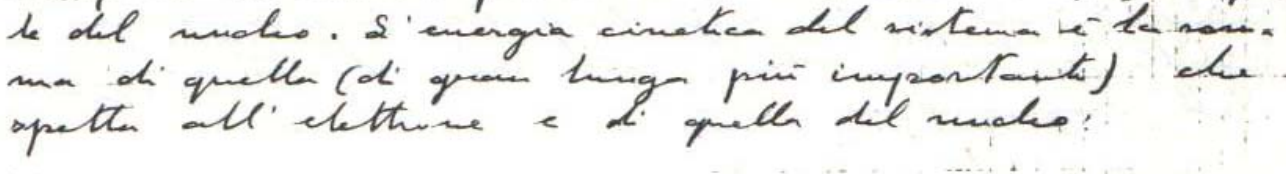

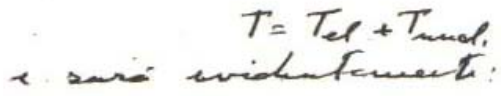

$$
\begin{aligned}
& T_{l}=\frac{1}{2} m\left(\dot{r}_{2}^{2}+r_{2}^{2} \phi^{2}\right)=\frac{1}{2} \frac{m M^{2}}{(m+M)^{2}}\left(z^{2}+r^{2} \dot{\varphi}^{2}\right) \\
& \begin{array}{l}
T_{\text {nnd }}=\frac{1}{2} M\left(r_{1}^{2}+r_{1}^{2} \dot{\varphi}^{2}\right)=\frac{1}{2} \frac{M m^{2}}{(M+m)^{2}}\left(r^{2}+r^{2} \dot{\varphi}^{2}\right) \\
\text { ind }
\end{array} \\
& \text { - quind } \\
& T=\frac{1}{2} m \frac{1}{1+\frac{m}{M}}\left(r^{2}+r^{2} \dot{\varphi}^{2}\right)=\frac{1}{2} m\left(r^{2}+r^{2} \dot{r}^{2}\right)
\end{aligned}
$$

Figure 1: Page of Majorana's notes taken from ref.[6], see text. 


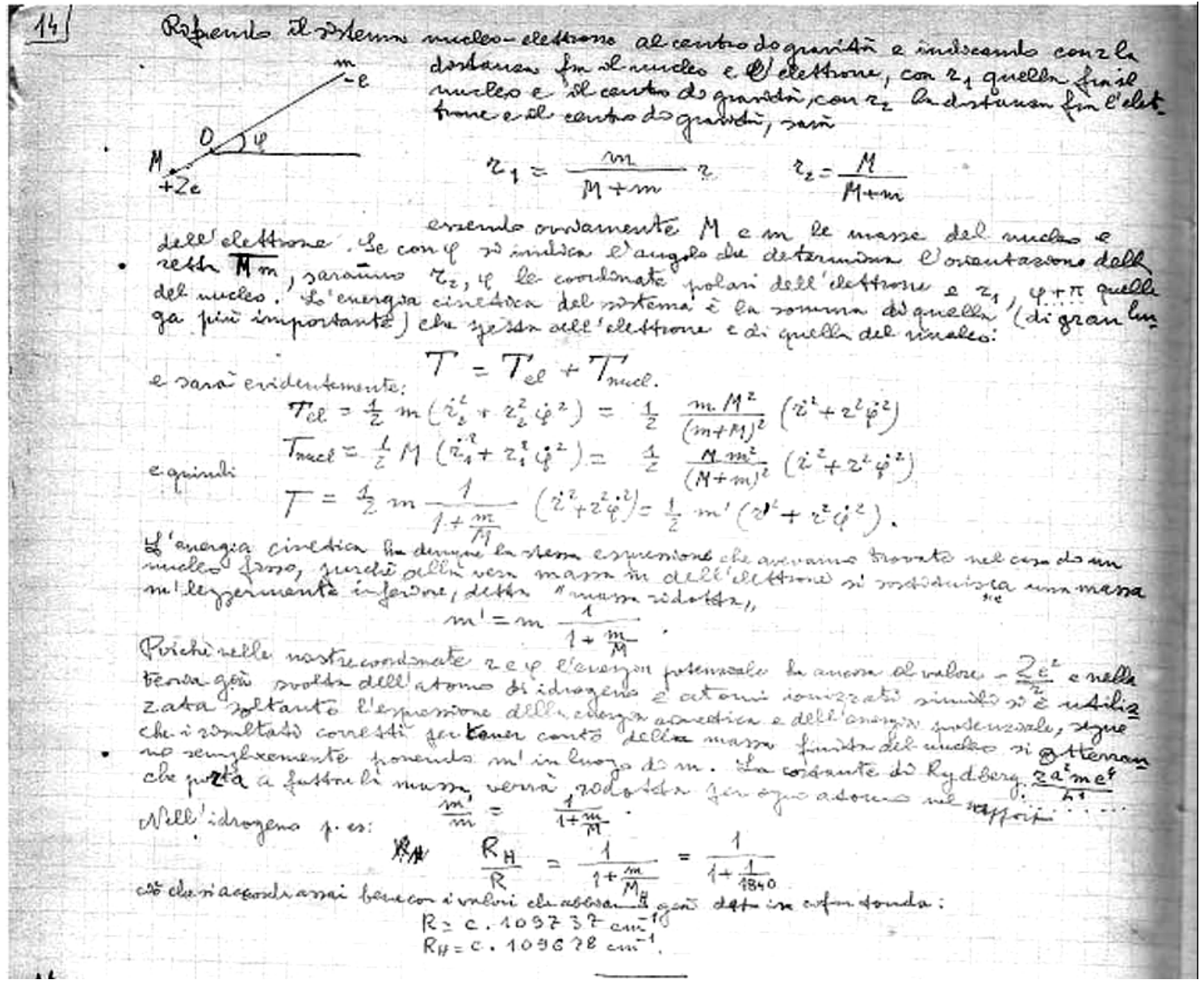

Figure 2: Page of Moreno's notes taken from ref.[7], see text.

reproduced, one which is contained in the book [10] and another one which is not contained there. When the first one is compared with the one present at page 21 of [6] , the identity of the two writings is perfect (in his notes, Majorana forgot a letter ' $r$ ', see Fig. 1 in writing the centre mass coordinates; this ' $r$ ' is missing also in the Moreno version, see Fig.2). This thing can be explained only in the hypothesis that Moreno had received the lecture notes arrived to Carrelli as described before. On the basis of the information given by Gilda Senatore and other colleagues of Carrelli, he and Caccioppoli were sincere friends; they occupied for 15 years contiguous chairs at the S. Carlo theatre and Carrelli always highly respected Caccioppoli and considered him the most important Neapolitan scientist. On the other hand, the fact that Savino Coronato, assistant of Caccioppoli during his entire life, who however never showed interest in physics, went to all the lectures of Majorana, may be interpreted only in terms of the will of Caccioppoli, who was strongly impressed by the Majorana inaugural lecture and who always showed a big interest in mathematical physics problems. I think then that Carrelli had given for a while the notes received by Cennamo to Caccioppoli, and this one had asked Moreno to copy them.

The Department of Physical Science and its section of the National Institute of Nuclear Physics have recently financed the publication of the notes written by Moreno [8], 
which are in any case the complete transcription of the lecture notes given by Majorana to Gilda Senatore. By the way, in occasion of the centenary of the birth of Majorana, the Italian Physical Society has published all the papers of Majorana, complete of their English translation, with comments of different authors [9].

Another information, which gives insights about the reason why some lectures notes seem to be missing, is derived from the University yearbook 1940, in which it is published that in that year Carrelli published "La teoria di relatività" as an issue of the "Gioventù Universitaria Fascista. This fact implies that the corresponding lectures were given in the academic year 1939-40. Tartaglione is sure that these issues were materially written by Nella Altieri and Laura Mercogliano. As the lectures missing in the Galilaean version concern the special relativity and the electrodynamics, which was in the interests of Carrelli, it is easy to argue that he took them away from the brief case and forgot to replace them in it.

\section{Majorana's disappearance}

The last question I want to refer has to do with the disappearance of Ettore. Always in 1998, Tartaglione gave me the following information.

At the end of years fifties, after prof.Carrelli's lecture at the Naval University Institute, he was used to walk along with him in the historical centre of Naples. Once they went by the S. Gregorio Armeno cloister and stopped to look at the restore works. As Tartaglione recalls, near the Bottiglieri's fountain, Carrelli pointed to some internal windows and said:

"Ettore Majorana practised his spiritual exercises in one of those cells".

"Is he still alive, then?", I asked.

He didn't reply and said: "Let's go back to the Institute. There are a lot of things to do, today".

S. Gregorio Armeno was a cloister for nuns. Nothing strange if some of its cells were temporarily used to accommodate some partecipants to a session of spiritual exercises, typically of a week. I asked him to visit S. Gregorio Armeno together, in order to have a precise idea of the place.

In that occasion, we stopped near the fountain and afterwards, we entered the church. There a friar was preparing the altar for a ceremony. At the end, he came closer and we took the occasion to ask him information concerning the practice of the spiritual exercises. He was extremely kind and made an interesting comparison between the confessor during the spiritual exercises and the university professor during his lecture; he gave also other details. He was so kind that I justified our interest, telling him that we, as physicists, were interested in a famous physicist, who a few decades before practiced these exercises. His glance became ironic and immediately after he went away because, he told, he had a lot of things to do. We followed him from a distance and saw him while entering into the very close (no more than twenty meters) and enormous Monastery of S. Lorenzo Maggiore, which has played an important role in the history of Naples. When outside, I proposed Tartaglione to give the same information to our rector, prof. Fulvio Tessitore, in order to secret it. A few days after, we were received by the rector, we gave him the information above, put in a small envelope inside a copy of the book published in 1987. At the end of this brief meeting I invited prof. Tessitore 
to consider the possibility of asking cardinal Giordano, archbishop of Naples, with whom he had very good relationship, whether Ettore Majorana had never passed through S. Lorenzo Maggiore. Years later, in occasion of a meeting, I asked prof. Tessitore whether cardinal Giordano had ever replied him. The answer was that the cardinal considered the question unacceptable (in Italian, 'irricevibile'). I conclude remembering that the mother of Ettore asked pope Pius XII to let her know whether her son was in some monastery, no matter which. The Vatican never replied.

\section{References}

[1] E. Amaldi, La vita e l'opera di E. Majorana, Accad. Nazionale dei Lincei, Roma 1966

[2] L. Sciascia, 'La scomparsa di Majorana', Torino, 1975

[3] B. Russo, ‘Ettore Majorana - Un giorno di Marzo’, Palermo, 1997\}

[4] Erasmo Recami, 'Il caso MAJORANA' , Mondadori ed. e Di Renzo ed., 2000

[5] Luisa Bonolis, 'Majorana, il genio scomparso’ Le scienze, giugno 2002

[6] Ettore Majorana, 'Lezioni all'Università di Napoli', a cura di B. Preziosi, Bibliopolis, 1987

[7] S. Esposito, 'Il corso di Fisica Teorica di Ettore Majorana: Il ritrovamento del documento Moreno’, Il nuovo Saggiatore, Vol. 21, 2005, p.21.

[8] S. Esposito, ‘Ettore Majorana, Lezioni di Fisica Teorica’, Bibliopolis 2006

[9] 'Ettore Majorana, SCIENTIFIC PAPERS', edited by F. Bassani et al., Italian Physical Society, 2006 